Georgetown University Institutional Repository http://www.library.georgetown.edu/digitalgeorgetown

The author made this article openly available online. Please tell us how this access affects you. Your story matters.

Heelan, P. "Husserl's Later Philosophy of Natural Science." Philosophy of Science 54 (1987): 368-390.

Collection Permanent Link: http://hdl.handle.net/10822/550879

(C) 1987 The University of Chicago Press

This material is made available online with the permission of the author, and in accordance with publisher policies. No further reproduction or distribution of this copy is permitted by electronic transmission or any other means. 


\title{
HUSSERL'S LATER PHILOSOPHY OF NATURAL SCIENCE
}

\author{
PATRICK A. HEELAN
}

\begin{abstract}
Husserl argues in the Crisis that the prevalent tradition of positive science in his time had a philosophical core, called by him "Galilean science", that mistook the quest for objective theory with the quest for truth. Husserl is here referring to Göttingen science of the Golden Years. For Husserl, theory "grows" out of the "soil" of the pre-scientific, that is, pre-theoretical, life-world. Scientific truth finally is to be sought not in theory but rather in the pragmatic-perceptual praxes of measurement. Husserl is faulted for taking measuring processes to be "infinitely perfectible". The dependence of new scientific phenomena on the existence of prior "pre-scientific" inductive praxis is analyzed, also Husserl's residual objectivism and failure to appreciate the hermeneutic character of measurement. Though not a scientific (theory-)realist, neither was he an instrumentalist, but he was a scientific (phenomena-)realist.
\end{abstract}

(Preprint 1987; “Husserl's Later Philosophy of Natural Science," Philosophy of Science, 54 (1987), 368-390. 


\title{
HUSSERL'S LATER PHILOSOPHY OF NATURAL SCIENCE $\dagger$
}

\author{
PATRICK A. HEELAN \\ Georgetown University \\ Washington, DC 20057
}

Edmund Husserl's contribution to the philosophy of the positive sciences comprises a critical element and a constructive one. The critical element is a vigorous and subtle philosophical critique of a certain notion of positive science the goal of which is the construction of an "objective [mathematical] theory". In this respect, Husserl is (in contemporary language) an anti-realist, that is, an anti-(theory-)realist. He says that objective theory does not possess an ontic (by ontic I mean real) sense, ${ }^{1}$ that is, does not express what really is. By contrast, the constructive element is a new focusing on natural science as the constitution of a new kind of empirical praxis in the life-world of the human community. For Husserl, it is the "subjective-relative" character of this praxis that gives an ontic sense to science. On this account, Husserl is not an instrumentalist, but a new kind of scientific realist, a scientific-(phenomena-)realist (where phenomenon means a perceptual object).

Such theses are found with greater or lesser clarity in Husserl's The Crisis of European Sciences and Transcendental Philosophy (1934-1937), in the "Vienna Lecture" (1935), and in the "Origins of Geometry" (1936). ${ }^{2}$ All of these works were written after the publication of' Martin Heidegger's Being and Time (1927) and may have been influenced by Hu s serl's reading of this great work. They greatly enlarge one's understanding of' the phenomenological tradition of philosophy, particularly of Husserl's attitude towards the natural sciences, and they introduce a genuinely new approach to a philosophy of the experimental sciences.

1. Husserl's The Crisis. The Crisis has three parts. In Part I, Husserl states that he views modern science within the general context of meta-physics and the history of Western philosophy. For Husserl, history has a special meaning; it is the story of the operative traditions we find sedimented in our present culture, ${ }^{3}$ and to tell this story is (in Husserl's term) a "genetic phenomenology". ${ }^{4}$ History studies the present in so far as it is the product of the past, for the past is always the past-forus, or more precisely the past-as-present-to-us-for-our-future. Such a notion of history (or "history"-in quotes - to distinguish it from other notions) may seem strange to us as it does to many historians. It is not the story of the past as past, but of the present as carrying forward in our own time projects shaped by past

(Preprint 1987; "Husserl's Later Philosophy of Natural Science," Philosophy of Science, 
interests and events. Husserl's contribution to the philosophy of science derives from reflections on contemporary scientific praxis considered from such a historical and metaphysical perspective.

Husserl takes the chief sedimented tradition of science to have a philosophical core derived from a certain moment in the historical search for thedria, inaugurated by Galileo, made philosophically explicit by Des-cartes in his Meditations, and consecrated by the work of Newton, Leibniz, and Kant. This he calls the tradition of "Galilean science". Husserl's critique of Galilean science is then fundamentally a critique of the Cartesian spirit. This critique comprises Part II of the Crisis.

Husserl's critique of (what he called) "Galilean science" derived from a grasp of the philosophical centrality of the life-world—of its "originality" as source and validating "ground" of all knowledge of reality. The "origins" of modern science, he believed, could be discerned intuitively even apodictically, in the practical and perceptual processes of measurement that take place in the life-world. Husserl's intuitive and reflexive method seeks its evidences within the contours of the human experience of (in this case) scientists as measurers. Dualism is overcome by showing that (even) watching or looking is a purposeful activity of a physical agent: what one sees is a function of how inquiry is actively pursued, its possible "kinestheses" (activities of the subject as a living body or Leib), and the expectations associated with these. Implicit in this critique is a turning towards experience; whether or not that means a turning away from theory depends very importantly on how one reads Part 1llA of the Crisis.

Beyond the duality of the historical subject and historical life-world and implicit in all such dualities, he concluded, there must be a set of final, unchanging, and definitive principles that ground all such human possibilities. This he called "the transcendental phenomenology of the life-world and of the transcendental Ego". These topics are treated in Parts 1I1A and 111B of the Crisis and elsewhere in Husserl's later works. ${ }^{5}$ I shall not speak much about this aspect of Husserl's philosophy except to say that his formulation of the transcendental question seems to include a certain residual objectivism about science and probably depends on deeper motivations not evidenced on the surface of the text.

One must say, finally, that Husserl's philosophy of science is not complete. The principle text on which we have to rely, the Crisis, is just a posthumous compilation of working papers in various degrees of completion intended for a book still unfinished at the time of his death. Their late appearance and the incompleteness of the text have been the source of many misunderstandings regarding Husserl's evaluation of the positive sciences, and such misunderstandings have often obscured the constructive contributions that Husserl made or sketched out regarding a philosophy of the praxis of scientific knowing and inquiring.

It would be a serious error to conclude from the subsequent history of

(Preprint 1987; "Husserl's Later Philosophy of Natural Science," Philosophy of Science, 
phenomenology that Husserl decried the value of theory making for natural science or thought little of the pursuit of science as a professional activity. He was a mathematician who delighted in theory, particularly in axiomatics. The similarity of thought and wording between Husserl's treatment of theory and axiomatics and Hilbert's suggests a general basis for agreement between them as to the theoretical goals of science. What Husserl criticized about science was not that it used mathematical models but that, (generally) led by a false metaphysics, it (generally) mistook them for reality.

2. Galilean Science as the Philosophical Core of Gottingen Science. Husserl was trained in mathematics as well as in philosophy. A student of the mathematician Weierstrass at the University of Halle, his early and abiding interest was the foundations of mathematics and logic. From 1901 until 1916, Husserl held an appointment as Extraordinarius at the University of Gottingen, before the separation of the faculties of mathematics and natural science from the faculty of philosophy. Those years were among the "Golden Years", before the Nazis came to power, when Gottingen's mathematicians and theoretical physicists constituted, perhaps, the most brilliant circle of its kind the world has ever known.

Among Husserl's colleagues at Gottingen were mathematicians such as Felix Klein-author of the Erlanger Programme ${ }^{6}$-Richard Courant, Hermann Minkowski, Hermann Weyl and, most important of all, David Hilbert. In relation to physics, Hilbert set the tone. "Physics is too difficult for physicists", he said. Physics needs the help of mathematicians to construct the ideal physics and the ideal physics has the form of theory, and all theory ideally has the form of an axiomatic system. ${ }^{7}$ The Gottingen school of natural scientists took science to be theory making. ${ }^{8}$ They had no experience of or interest in how experimental physics was done since they regarded it as unproductive without the leadership of mathematics. This view came to be shared by the leaders of the physics community such as, notably, Albert Einstein, Werner Heisenberg, Erwin Schrodinger, and John von Neumann. ${ }^{9}$ Looking back today at the achievements of physics since 1900 that comprise the greatest expansion of cosmological knowledge in human history, we recognize that they were in fact due to the leadership the Gottingen school gave to physics during this period. But we must beware of the fallacy of thinking that the consequent success of

Gottingen physics justifies the philosophical premises on which it is often based. Husserl wants to put us on our guard.

The core of Gottingen science was mathematical theory building. To the extent that such theory building constituted an implicit metaphysics, Husserl called it "Galilean science". Why the name? Although foreshadowed by

(Preprint 1987; "Husserl's Later Philosophy of Natural Science," Philosophy of Science, 
Pythagorus, Plato, Euclid, and Archimedes, such a characteristically modern kind of mathematical-experimental science made its appearance with Galileo's successful mathematical treatment of falling bodies. However, what Husserl called "Galilean science" is rather a certain meta-physical project that (he claims) animated the science of Galileo, Des-cartes, Newton, and Kant, that was handed down by a continuous tradition, and that constituted the philosophical core of the most prevalent and authoritative tradition of professional science in his lifetime (compare C, p. 347). Galilean science then is the essence, the "thing itself" revealed in and through the best practice of science of his time, namely, of Gottingen science. ${ }^{10}$ This practice was something that Husserl was in an excellent position to know ${ }^{11}$

What are the characteristics of Galilean science? The "new" "unprecedented" characteristics of mathematical natural science is that "through Galileo's mathematization of nature, nature itself is idealized under the guidance of the new mathematics; nature itself becomes . . . a mathematical manifold", that is, there is "the surreptitious substitution of the mathematically substructed world of idealities for the only real world, the one that is actually given through perception, that is ever experienced and experienceable-our everyday life-world". (C, pp. 23, 48-49; compare VL pp. 277-278). ${ }^{12}$

Crucial here are the terms "real" and "ideal": "real" is applicable solely to perceptible embodied particulars (of certain kinds) and "ideal" is applicable solely to imperceptible disembodied absolutes or idealities (lacking the spacetime particularity that characterizes the real $)^{13}$ Ideal objects, unlike particulars, are unique and self-identical. For example, there is only one number four. The number four, like, for example, the essential kind apple, has the kind of objectivity that all ideal entities possess, that is, each is unique (there is only one number four), universal (wherever and whenever it occurs it is exactly the same), and absolute (to whomever it presents itself, it presents itself in an identical non-subject-relative way). ${ }^{14}$

What is true of numbers is also true of geometrical and other mathematical entities. The ideality and objectivity of such entities means that they cannot be multiplied. Each geometrical line is unique (but it is not a particular), and likewise each triangle, each circle, each number, etc. Given the unicity of the ideal, different lines and numbers must be differentiated among themselves and from one another not by any sensible matter they inform but by the structure of the ideal spaces or space-times they comprise. Ideal entities such as mathematical ones having escaped as it would seem all relativity to human beings and cultural history belong rightly to the absolute realm of (what Husserl and others call) being-initself. How the objective ideal is, could, or should be related to the subjective-relative real is a complex matter that will be discussed below.

(Preprint 1987; "Husserl's Later Philosophy of Natural Science," Philosophy of Science, 
3. Objective Theory and Scientific Realism. Returning to Husserl's account of the mathematization of nature, Husserl takes Galilean science to be a part of the search for "the 'objective truth' of this world", for "what, in this world, is unconditionally valid for every rational being", for "what it is in itself" (C, p. 68). Galilean science expresses this goal by affirming the objective truth of scientific theory taken in its ideality. Such a position he calls "objectivism"; ${ }^{15}$ it is a form of what is called today "Scientific Realism".

Husserl finds that the quest for certainty and objectivity that is modern science is founded on the central insight of the Cartesian Cogito. This was interpreted (following Descartes' own treatment) as revealing the empirical Ego to be a pure logical-rational Mind stripped of any essential relationship to a life-world. This conclusion Husserl does not accept, "for animal spirituality, that of human or animal 'souls', to which all other spirituality must be traced back, is individually, causally founded in corporiety" (VL, p. 271). Consequently, he argues, objective theoretical science arises out of a certain subjective-relative praxis evidentially grounded in the conditions of the lifeworld of the historical community of which scientists are a part and only a part. Central to this praxis is measurement. Measurement, he says, is an "infinitely perfectible" process that con-verges in the limit on a number measure that is an ideal constituent of theory. ${ }^{16}$ By measurement, space-time is "directly mathematizable", and by measurement, sensible qualities are "indirectly mathematizable".

4. Space-Time as Directly Mathematizable. Although there existed a continuous tradition of measurement linking antiquity with the present time, it was in modern times that, according to Husserl, measurement came to be constitutive of the structure of lived space (see C, p. 27; compare OG, pp. 353378). How such a constitution is enacted needs explanation.

Consider first the constitution of the spatiotemporality of (the perceptual bodies of) the life-world. The living human body (Leib), says Husserl, is "essentially different" (C, p. 107) from inanimate physical bodies (Körper) because it is self-moving, it has bodily kinestheses through which it explores the bodily characteristics of other bodies and in which these bodily characteristics are represented.

What then is the bodily character of a perceptual object? A body has this characteristic that it shows itself not all at once, but perspectivally, in time. ${ }^{17}$ The many variable perspectival views or profiles of a body flow one into another according to the particular law executable in time that strings them into a coherent

(Preprint 1987; "Husserl's Later Philosophy of Natural Science," Philosophy of Science, 
whole. The horizon of a body, Husserl concluded, is the temporal invariant of a manifold of perceptual profiles generated by a group of transformations among them. ${ }^{18}$

To the variety of appearances through which a body is perceivable as this one-and-the-same body correspond, in their own way, the kinestheses [in the subject) which belong to this body; as these kinestheses are allowed to run their course, the corresponding required appearances must show up in order to be appearances of this body at all, i.e., in order to be appearances which exhibit in themselves this body with its properties. (C, pp. 107, 161-162).

The mutual involvement of subject (you, the observer) and object (it, the observed) in the process of perception can be understood in the following reconstruction that brings out incidentally the influence of Klein's conception of geometry on Husserl's conception of lived space. Imagine two scenarios: in the first of passive scenario, the object plays out its dramatic role before your eyes without your intervention. You are the audience, the passive spectator of this show in which the object exhibits a continuous sequence of transitions among its profiles, each transition generated by a sample of its transformation group (the transformations that act on a profile to produce another profile constitutive of a group); under these transformations the object remains the same for the observer throughout the changes of appearance. In the alternative or active scenario, you play an active role. For every sequence of profile changes associated with a certain transformation of the object, there are actions you could perform that would have the equivalent effect. If the object is turned around in a clockwise direction, this brings into your view the same sequence of profiles as you would see if you chose to move around the object in the anticlockwise direction. In natural perception, no instruments are used, but there is nothing precluding the use of a common repertory of standard instruments, such as clocks, rulers, and even more complicated instruments to change the profile of the object.

Such an analysis is familiar to theoretical physicists, particularly in elementary particle physics. They would call the transformation group of the object the active transformation group, and the transformation group of the observer (here, the viewing subject) the passive transformation group. ${ }^{19}$ They are identically the same group looked at from the point of view of the observer and of the object. Each will have a set of invariants that define on the one hand the horizon (technically, the "representation") of the object or its essential kind and on the other hand the horizon (technically, the "representation") of its counterpart in the subject. In this way subjectivity and objectivity, noesis and noema, mutually "mirror" one another.

How is the spatio-temporality of a body "mirrored" in the Leib of the

(Preprint 1987; "Husserl's Later Philosophy of Natural Science," Philosophy of Science, 
perceiving subject? Husserl takes it to be through the program of the passive scenario; this program is Husserl's Sinn. ${ }^{20}$ This is a program for practical action, like a musical score, capable of directing the living body (Leib) in how to use its bodily kinestheses and the resources of the environment (including, let me add, technologies) in order to bring successively into perceptual view the themes or melodies of profiles that define the spatiotemporal invariances of the perceptual object. The spatio-temporal representation of the object then within the subject-that is, how it is "mirrored"-is not like a typical picture of the object, rather it is the competence to enact or to receive in a particular case the active and passive scenarios through which a body exhibits itself to a mobile observer in characteristic sequences of its spatio-temporal shapes and figures. ${ }^{21}$

5. Mathematizing Space-Time. Such perceptible spatiotemporal shapes and figures, says Husserl, are directly mathematizable, and in being mathematized, they become geometrical-ideal bodies. Geometrical-ideal shapes are, of course, not themselves perceptible; how then are they related to what is perceivable? Husserl answers: perceptible shapes "in actuality or fantasy, are thinkable only in gradations: the more or less straight, flat, circular, etc." (C, p. 25). The axiomatic elementary laws of pure geometry that determine the meaning of straight, flat, circular, etc. are understood immediately "by an 'innate' faculty (as it is called) of knowing with definiteness true being-in-itself as mathematically ideal being (before all actual experience)". "Thus", he concludes, "implicitly the space-time form is itself innate in us" (C, p. 54). What concretely exists in nature, and how this geometry is applied in experience is learned through the technical art of measuring. Measuring is the praxis that links the real to the ideal. As long then as measurement is governed merely by practical interests, he says, there is no need for an ideal limit. But, "out of the praxis of perfecting, of freely pressing toward the horizon of conceivable perfecting 'again and again,' limit-shapes emerge toward which the particular series of perfectings tend, as toward invariant and never attainable poles" (C, p. 26).

How the ideal is, could, or should be related to the real is a complex matter as I shall explain. While all measured values are ideal (since they are mathematical), they do not in every case - contrary to what Husserl thoughtimply the existence of a limit, much less, of a unique limit. (I take limit to imply something like Hilbert's axiom of continuity for physics; there are values to which measurement can get arbitrarily close.) Key to an understanding of mathematical idealization in the Crisis are the notions of approximation and limit, and infinitely perfectible technologies of measurement.

Before examining how an "infinitely perfectible" measuring process

(Preprint 1987; "Husserl's Later Philosophy of Natural Science," Philosophy of Science, 54 (1987), 368-390. 
generates an ideal limit, we must inquire how a real process-an act of measurement-performed in the life-world can produce as its outcome an ideal entity, that is, a number. Since a number is neither a physical nor a perceptual entity, a number assignment needs an interpreter, the scientist who knows how to make the assignment of a value on the basis of sensible signs generated by the measurement interaction. Even when the outcome of the measurement is directly written, say, on paper, what is written is merely a sign (or signifier), for example, a numeral or a graph, but how the sign is to be read, whether a value is to be given to it and what value is to be given, is to be determined by a competent judge, usually a scientist. The outcome of a particular measurement is then the recognition of a real numerical particular (that is, of a particular whose ideal essence is the measured value).

It is interpretation, then, that idealizes in measurement. Interpretation idealizes, first of all, by introducing an ideal entity, number. In addition, there is sometimes another idealization by way of a limiting process that relates an approximate to an exact number. These are two different processes. A single isolated measurement moves from a sensible sign (by a "reading" or interpretation) to an ideal (measured value). Such an ideal, however, may itself be only approximate in relation to some limit taken as the true value, or its experimental status may not involve limits, but instead the satisfaction of a pragmatic competence or skill. I will hold that good scientific practice is content with pragmatic competence; limiting processes, however, belong not to reality, but only to mathematics.

To explore further what this means, we ask how, for example, is a sensible line (drawn, say, with a ruler on a sheet of paper) related to an ideal geometrical line? This relationship Husserl takes to be self-evident. ${ }^{22}$ Such self-evidence, of course, attaches to the fact that we can do geometry by drawing lines, but it does not extend to the (transcendental) principles that make possible such a doing. We may then legitimately inquire: is the drawn line 1. an approximation to a limit (as Husserl proposes), or 2. a real particular of an ideal (geometrical) essence, or 3. just one profile (perspective) of a real particular of an ideal (geometrical) essence? I cannot here discuss the grounds for stating that the correct answer is 3.

Husserl, however, seems to affirm 1. and 2. His position then would include both of the following: that the geometrical line is an essential kind relative to real particulars for which it is the essential kind, and that the essential kind is a limit relative to an ordered sequence of infinitely perfectible particulars (for him, drawn lines). These views are not compatible with one another, for an essential kind is an ideal and a limit of particulars-if that makes sense-must also be a particular.

(Preprint 1987; "Husserl's Later Philosophy of Natural Science," Philosophy of Science, 
But there is no need to assume that the sequence of particulars-and the technologies necessary to produce or recognize them-is infinitely perfectible. It is not. Husserl made the (classical Galilean) assumption that scientists would always be interested in rulers as infinitely perfectible (compare C, p. 139), and from this perspective, infinite perfectibility seems to remove the last traces of historical subjectivity from the specification of the ideal limit (C, p. 111; compare C, pp. 343-351).

In practical life, that is, in the life-world, real particulars are always qualified as relative to the historical satisfaction of the experienced subject's practical competence. It did not occur to Husserl with his classical mathematical training - or to Hilbert for that matter-that the scientist too as an interpreter of the world might not be interested in rulers as infinitely perfectible but as perfectible just up to a point. Good scientific practice takes it for granted that it is not the case that any scientific measuring process is infinitely perfectible. There may or may not be a theoretical law, such as the quantum theory provides in relation to classical physics, limiting the precision with which numbers can be read from possible measurement processes. But even where there is such a law, this law itself has practical limits requiring special competence to apply it correctly, and these point to the recurrence of the same problem at a deeper level. Experience with experimental processes indicates that for every kind of measurement process, there is an optimal level of precision beyond which the validity of background assumptions fail. ${ }^{23}$ Hilbert's axiom of continuity for physics applies only to the models of physics, not its data. At what point for a given technology the boundary is likely to be transgressed is not generally derivable from the theory itself. Such a determination is generally a matter of practical competence and good judgment or what Aristotle called "phronesis". Scientific theory needs to be complemented by the phronesis of the historical experimental scientist if real particulars of a scientific phenomenon are to be produced or recognized in the historical life-world.

Unlike an infinite series of mathematically related terms (such as $1 / 2$ "), an indefinitely large experimental sample of measured numbers related by the fact that they were all produced by the same measuring process does not generally have a unique limit, for different subsequences may well converge to different limits. The existence of a unique ideal limit is not then inductively guaranteed. To assume that one limit exists is an a priori assumption that contradicts the best practice of measurement. Such a conflict between the transcendental a priori background of measurement as posited by Kant, Husserl, and the prevalent scientific view (generally) and the understanding that good practitioners generally have of measurement suggests a different-in fact, hermeneutical and historical-resolution to the same transcendental question.

(Preprint 1987; "Husserl's Later Philosophy of Natural Science," Philosophy of Science, 
6. Sensible Qualities. Sensible qualities of the plena-colors, tones, warmth, etc. that "fill out" the bodily shapes of things-come to be mathematized indirectly, that is, by discovering some measurable events, such as wavelengths or other spatial properties, that serve as "indices" of these sensible qualities. The ancient Pythagoreans, for instance, discovered the dependency of tone pitch on the length of a vibrating string. To each sensible quality there will be an "index" and a technological praxis to measure it by representing it as proportional to some length; the measure of such a length involves the idealized representation of space-time. In this way the sensible qualities of the plena are mathematized indirectly and, like spatial extension, are replaced by ideal values in an idealized spatial representation of the qualities.

Although a sensible quality $X$ does not have the same meaning (Sinn) as that defined by the measurement praxis that provides its scientific index, measured $\mathrm{X}$; nevertheless, Husserl assumed the relation between the real sensible quality $X$ and the measured value $X$ is - like the relation he took to exist between a sensible line and its geometrical essence - that of the approximate to its limit. Such seems to be the burden of Husserl's words, "objective science . . . sets itself the task of transposing knowledge which is imperfect and prescientific in respect of scope and constancy into perfect knowledge - in accord with an idea of a correlative which is, for sure, infinitely distant, i.e., of a world which in itself is fixed and determined and of truths which are idealiter scientific ('truths-in-themselves') and which predicatively interpret the world" (C, p. 111; compare C, p. 139).

The dialectic between the pairs, approximate and limit, real and ideal, perspective and particular, is in this case analogous to that for space-time, and I shall not go over it again. However, with respect to the material identity between sensible $X$ and measured X, some distinctions and criticisms have to be made. But before embarking on this, we need to consider the character of the pre-scientific life-world, and how Husserl thought objective theoretical science to be foreshadowed, tested, and verified in its structure.

7. The Pre-scientific Life-World. For Husserl, the life-world is "the intuitive surrounding world of life, pre-given for all in common" (C, p. 121). It "includes all our goals, all our ends, whether fleeting or lasting, in a flowing constant manner, just as an intentional horizon-consciousness implicitly 'encompasses' everything in advance" (C, p. 144). It is not an object-if it were, it would fall prey to Kant's critique - it is not a particular of a kind, nor is it any kind of thing, nor above all is it a conceptual framework. It is rather the universe of what is; its universality, however, is not ideal but concrete. It is the ultimate pre-given horizon of all perceptible objects and practical goals (C, pp. 142-143). Among the praxes pursued within it, is the

(Preprint 1987; "Husserl's Later Philosophy of Natural Science," Philosophy of Science, 
pursuit of theoretical science (C, p. 136). It is "the point of departure [for all theoretical science), both historically and for each new student" (C, p. 121) and the practice of science "continues to presuppose this surrounding world as it is given in its particularity to the scientist" (C, p. 121).

The life-world is obviously not a buzzing blooming chaos of sense-data but the way ultimate reality is given to people structured by the historical practical horizons towards which people direct their lives. It is the product of past cultural traditions that are sedimented within it and that exercise their power over the present and future through the contemporary praxes they support. Nevertheless, the life-world is always contemporary, and being intrinsically "historical" (in the sense just mentioned), it gives meaning to "history". ${ }^{24}$

We must distinguish between life-world as naively appropriated and as appropriated critically. The contemporary life-world contains both the praxis of theoretical science and that privileged interpretation of theory that Galileo and Descartes have handed down to us. Western culture like the prevalent tradition of science has a strong bias to take the ontic to be the content of objectivetheoretical models. Such a bias, Husserl says, must be removed from the naive life-world if we are to rediscover the totally subjective-relative matrix that is the true source of ontic meaning for science. The bias is removed by "the epoche of objective science" (C, p. 135). The contemporary life-world purified of this bias is what Husserl calls the "pre-scientific life-world"; it is the critical starting point for an ontological appropriation of the life-world.

But what is the pre-scientific life-world? The name is in many ways confusing. The prefix "pre-" generally refers to a time before something came to be, but the pre-scientific life-world could hardly be what the life-world was before science, because the life-world is always contemporary. It must mean the life-world under some current aspect; that is, as pruned or otherwise transformed by "the epochs of objective science". But how?

Such an "epoche" (or "bracketing") means that "we may use no sort of knowledge arising from the sciences as premises" (C, p. 147). What is left is the life-world as pruned of all meanings and phenomena that are logically or methodologically dependent on the use of objective theory. This is really the pretheoretical world but, as Husserl claims, it is not without a sedimentation of scientific artifacts. Many of the technologies of science, he says, remain and much of its "inductive praxis", such as "[seeing] measuring instruments", "[hearing] time beats", and "[estimating] visible magnitudes" (C, p. 121). This is confusing since, if science (as Galilean) is nothing but the "praxis of making theories", some rationale other than theory has to be found to establish the presence of such technological phenomena in a pre-theoretical world. Nevertheless, Husserl assumes that they remain pre-theoretically as identifiable

(Preprint 1987; "Husserl's Later Philosophy of Natural Science," Philosophy of Science, 
material phenomena, that is, as describable with the vocabulary of science but minus its theoretical concepts.

Is there then a way of categorizing such artifacts of science that is not theoryladen? Can the sedimented technologies of science be recognized or determined without recourse to theory? The answer distinguishes among members of a culture. Consider the life-world pre-given to a child. It is for the child a pretheoretical life-world, but it is nevertheless for the child not without sedimentations of scientific praxis (attended to, of course, by his or her teachers). The child's experience of such a world is what Husserl calls "pre-predicative", in the sense that, even before its predicates are known, it is experienced in a way structured by the predicates it would be found to have. ${ }^{25}$ It is, for example, pre-predicatively Euclidean rather than non-Euclidean-a point to be taken up below-even for those who know nothing of Euclidean or non-Euclidean geometry. Euclidean spatial horizons are handed on to a child of this generation through his or her cultural embodiments in a surrounding world (I shall give reasons below why they are not just a legacy from our biological past). This surrounding world is a world historically transformed by human energy into one where Euclidean modularity is written large in the artifacts that surround us. Note that the child's world is not for anyone devoid of the characteristic products of science but it is for the child-and for many others too-a pre-theoretical world. The process of discovery for a child is a species of (what Husserl calls) "induction" of which, he says, it is a "mixture of instinct and method" (C, p. 40). ${ }^{26}$

A new and revised view of science as a constructive theory-led praxis within the life-world implies that science ultimately deposits in our environment material structures that serve as clues from which others, such as our children or our students, can rediscover its theories by a species of "induction". The goal of science as a praxis in the life-world - that is, the ontological goal of science-is not then just theory-making but leaving theory behind it eventually enriches the life-world with new scientific phenomena mediated by the sedimented technologies science has produced. Among such phenomena are, for instance, Euclidean spatial structures, inertial motions, magnetic fields, electrons, and even galaxies. Through well-designed sedimented technologies such as instrumentation these acquire active and active profiles that are available to all even to those with minimum scientific competence and to those who know no theory or have forgotten it. Such phenomena can establish themselves in the life-world for all both as scientific (in the new sense) and nevertheless pre-theoretical (pre-scientific in the old sense).

8. The Pre-scientific Life-World as the "Soil" From Which Science Grows. Husserl has claimed that the pre-scientific life-world is the a priori origin, "the soil" (C, p. 131) of all theoretical science through the inductive discovery that certain infinitely perfectible measuring procedures converge on an ideal 
mathematical limit. Such a claim accepts the identification of science with theory, and theoretical models as limits of practical approximations. A priori to theory, then, there must already be an inductive praxis in the life-world, such as the use of rulers to measure spatial intervals or of string lengths to measure pitch. This raises several troublesome questions. I. How valid is the assumption that, when a sensible quality is measured, what is measured in this way is (denotationally) the samethough perhaps transformed in meaning (Sinn) - as the sensible quality that is experienced prior to measurement? 2. Is it the case that every new scientific praxis of measurement is a way of infinitely perfecting an old pre-theoretical inductive praxis of measurement? Husserl seems to have thought so. But if Husserl is wrong - as I believe he is-then, 3. we need to ask: how can a noninductive praxis that has the capacity to generate a new scientific phenomenon, such as, for example, the electron, come to be established in the life-world by a theoretically oriented science?

1. If it were true that a real sensible quality $X-a$ color, a tone, warmth, etc. - is the same (denotationally) as given by a measuring praxis for $\mathrm{X}$ that provides its index, then of the two realities, sensible quality $X$ and the real measured X (the scientific phenomenon, its scientific counter-part), surely one is expendable. For what would be lost from the life-world if measurement processes replaced sensible qualities in our ontologies except the special sense in which these are related to the human sensory system? So argue scientific realists such as W. Sellars. ${ }^{27}$

A similar conclusion seems to follow from Husserl's treatment of spacetime, for if intuited space-time has the same structure as measured space-time, then intuited space-time can likewise be replaced by measured space-time. If science can make all the discriminations that human perception can make and can do so more precisely-with fewer anomalies-then, argue the scientific realists, science is the most powerful, reliable, economical, and least subjective form of knowledge.

One has to go to the work of Merleau-Ponty and more recent writers ${ }^{28}$ in order to find a reply to this argument. Husserl is too close to the classical scientific tradition to appreciate that our spatial intuition may itself be of many kinds and historical, that it may not be primordially Euclidean and, moreover, that sensible qualities as experienced in the general con-text of human life may not be (denotationally) the same as any set of measured scientific quantities.

In a recent book, ${ }^{29}$ I marshaled evidence from various sources-contemporary everyday experience, the history of pictorial art, the structure of visual illusions-to show that we do possess a practical non-Euclidean spatial intuition (having the structure roughly of the family of hyperbolic Riemannian 3D spaces) that automatically shows things in a space that has two qualitatively different zones,

(Preprint 1987; "Husserl's Later Philosophy of Natural Science," Philosophy of Science, 
near and far, differentiated by the interests the perceiver has in what is being shown. I argue that non-Euclidean intuition is primordial and biologically oriented in its interests, while the development of a universal spatial intuition of a Euclidean kind was a historical process and systematically oriented to a technologically equipped community able to pursue interests beyond the biological. Euclidean spatial intuition emerged first in Northern Italy in the late fourteenth century and spread from there to the rest of Europe and beyond. This process was probably mediated by a transformation of the environment by human technologies into one where measured values dominated through the linearity and modularity of architectural and other artifactual forms, and by the availability of a well-developed Euclidean geometry to carry its meaning.

Whether or not one accepts this account of the origins (in the phenomenological sense) of Euclidean intuition as following an earlier and still present capacity for a more biologically oriented intuition matters less than the illustration it gives of what it would mean to hold that the ontic reality of the life-world is historical and richer in horizons than native human sensibility alone provides. Sensible qualities-sensible $X$-may not be related to their scientific counterparts-measured $\mathrm{X}$-in a one-to-one way, just as primordial non-Euclidean intuition is not related to cultural Euclidean intuition in this way. Just as the Sinn of measurement involves interpretation-making measurement a hermeneutical process-so processes of measurement initiated hermeneutically can become forms of practical intuition, interiorized through familiarity with the "feel" of standardized instrumentation. Hermeneutics then is not opposed to perception, rather we are led to the thesis that all forms of perception-relative to what Husserl calls their Sinn-are intrinsically or existentially hermeneutical, and as a consequence, historical. Even before theory has been deciphered and even after theory has been forgotten, perceptual horizons are ontologically shaped by human action and technological feasibility and perception is ontologically_but not necessarily consciously-structured by theory and interpretation. ${ }^{30}$

If all perception is hermeneutical, then every act of perception is motivated by a context of human interests and competences. The biologically oriented interests that are satisfied by primordial spatial intuition are different from the later cultural interests satisfied by Euclidean intuition: one is oriented with respect to the technologically unaided human individual, the other is systematically oriented with respect to a universal technologically equipped community. I do not claim that Husserl reached such conclusions, but only that they follow by a natural development from the incomplete and imperfect treatment that he has left in the Crisis and in his later works.

What is true for the intuition of space is also true for the intuition of sensible

(Preprint 1987; "Husserl's Later Philosophy of Natural Science," Philosophy of Science, 
qualities. in both cases the difference lies in the different physical and hermeneutical contexts of the horizons that show themselves to the perceiver. Sensible horizons are, like primordial space, biologically oriented with respect to the technologically unaided individual; measurable horizons, like Euclidean space, belong to a different systematization oriented with respect to a universal technologically equipped community able to pursue interests beyond the biological. The former are deeply and primordially structured by the goals of primitive culture ( 1 mean, culture not yet dominated by a technologically transformed environment); the latter are factually the product of cultural and historical choices motivated by Galilean science (the prevalent intellectual thrust of modern times) and embodied in the environmental products and technologies developed by the new science. Since these latter are in principle liberated from the protective but blind constraints of primitive nature and biology, the new technological powers are open to an infinite variety of different-Western and non-Western-cultural horizons.

2. Is every scientific praxis of measurement a way of infinitely perfecting a pre-theoretical inductive praxis of measurement? Husserl seems to have thought so. But such a resolution is a residual form of objectivism, for it suggests that there is a mathematical model to which the world as measured conforms as to an ideal ahistorical limit independently of the historical purposes of the people who measure. Such a conclusion leads inevitably either to transcendental idealism or back to a rationalistic form of realism. Since limits and the infinite perfectibility of measurement were treated above, let me consider here the question as to whether mod-em scientific measurement practices depend on the pre-existence in the life-world of a prescientific inductive praxis.

While it is plausible that some modem scientific measurement practices derive from ancient practices, such as those of surveying land or of measuring pitch by the length of a vibrating string, it is inconceivable that such practices were themselves primordial or that all current experimental practices have such ancestors. Some scientific entities, such as, for ex-ample, electrons, just did not have a sensible pre-theoretical presence in the life-world before modern science. Experimental practice related to electrons, for example, has first to produce the electrons that are to be studied. This is done by a standardized theoretically controlled process called "preparation of state" (also called "measurement of the second kind"). Are then electrons real particulars of a new scientific kind, new scientific phenomena of a life-world enriched by a scientific process of "preparation of state"? Since there is no pre-theoretical inductive praxis in regard to them, many phenomenologists - and others - conclude that they cannot be real phenomena like trees and stars but are merely theoretical artifacts invented for the control of nature

(Preprint 1987; "Husserl's Later Philosophy of Natural Science," Philosophy of Science, 
It would be well, then, to review the evidence in favor of the view that electrons, electron beams, etc. are truly perceptual phenomena, even though they are (in necessary part) products of scientific theory making. Although electrons are not sensible to the unaided senses, they serve as manipulable components of thousands of technologies-both within and outside scientific laboratories - and the reason they can so serve is that they exhibit stable, predictable profiles, both active and passive, to competent observers-usually experimental scientists skilled in the use of standard laboratory apparatus. If any procedure from which one can get or produce information about a scientific state can be called a measurement process (in the broadest sense), then every process that serves to manipulate electrons in predictable ways to produce sensible outcomes is a measurement process. All experimental inquiry then falls under measurement (in the broadest sense), and the final accomplishment of measurement is such control as provides competence to sample at will the active and active profiles of scientific entities such as electrons.

I suppose that today most scientific entities, such as DNA, synaptic potentials, gluons, etc., are just not usefully thought of outside of the laboratory as related to pre-theoretical inductive praxis of any sort. Nevertheless, each entity has the potentiality not merely of making its specific presence felt in the life-world through standard instruments and technologies, but of acquiring a stable even apodictic set of active and passive profiles with respect to suitably equipped and competent human subjects. Such profiles can often be sampled even by theoretically illiterate observers.

Returning now to Husserl's example of a sensible quality (sensible $\mathrm{X}$ ) and the scientific phenomenon (measured $X$ ) associated with it: each, I have argued, is constituted by a different material praxis and a different set of hermeneutical interests. The association between the two-though real-is then only partial and deeply affected by biology, history and culture.

The question as to whether every scientific process of measurement implies a historically antecedent pre-theoretical praxis of measurement must then be answered negatively. This answer, however, has to be qualified. Once a new scientific phenomenon is embodied in material structures of the environment, and once these structures become part of the cultural tradition of the pre-theoretical life-world of a community, then the "soil" is prepared as "originary" for the rediscovery by each new generation of students of the theory for such phenomena by (what Husserl calls) a process of induction.

Finally, 3: How do new scientific phenomena come to be established in the life-world by a theoretically oriented science? How can a non-inductive praxis-one that has the capacity to generate a new scientific phenomenon

(Preprint 1987; "Husserl's Later Philosophy of Natural Science," Philosophy of Science, 
such as, for example, any of the phenomena mentioned above-get a footing in the life-world'?

A reader sensitive to the problematic of the Crisis would have to say that such a question is not addressed in the Crisis. Such a question asks us to compare the life-world of one time with the life-world of another time, and that is not what genetic phenomenology does, nor for that mat-ter is this the goal of historical inquiry as Husserl understands it. Genetic method-and "history"-inquires about the traditions sedimented in the present life-world, and searches for their "origins" in the way the "historical" past is immanent in the present, giving it sense and goals. "What is historically primary in itself is the present" (OG, p. 373). The "historical" past is not then some state of the life-world that has gone by, for, if it were, it would no longer be open for us today to intuit or read. It is our present life-world that is the totality of all we could come to know with apodicticity. "IT]he whole of the cultural present, understood as a totality, 'implies' the whole of the cultural past in an undetermined but structurally determined generality" (OG, p. 371).

While we could, of course, fantasize or pretend that a phenomenon is not part of our world and ask how it might subsequently come to be established in our world, such research would lack the apodicticity of life-world evidences. To frame such a question within the context of the Crisis, we would first have to frame the question about the present: what are the (transcendental) conditions that make possible the progress to-wards reality status in the lifeworld of such present candidates as, for example, gravity waves, black holes, and quarks, given that the practices of good science are critically appropriated? Some additional light on such a question can be gleaned from Husserl's other later works, for example, Ideas 11, Formal and Transcendental Logic, and Experience and Judgment, but there is no clear story.

I have already by implication offered a tentative answer to this third question. It contains three parts: (i) the ideality of theory is not, in general, relative to infinitely perfectible measuring processes but relative to the purposefulness of the living body (Leib); (ii) perception is intrinsically governed by bodily kinestheses and essentially hermeneutical in relation to the purposefulness of Leib; and (iii) the living body, Leib, can use technological extensions within its perceptual praxis. None of these theses was actually formulated by Husserl. The first thesis is the contribution of this essay to a critique of the Crisis. The second is implicit in Heidegger's Being and Time and is also much discussed today by others. ${ }^{31}$

The third thesis was up by Merleau-Ponty in his posthumous work, The Visible and the Invisible, and is also being actively explored today. ${ }^{32}$ It is not difficult to see i $n$ retrospect that none of these theses is totally foreign to the dynamic of Husserl's

(Preprint 1987; "Husserl's Later Philosophy of Natural Science," Philosophy of Science, 


\section{Preprint 1987: Husserl's Later Philosophy of Natural Science}

later oeuvres.

* Acknowledgements: I want to acknowledge with gratitude the helpful discussions I have had with Joseph Kockelmans, Robert Sokolowski, Donn Welton, Claude Evans, and many graduate students at SUNY, Stony Brook.

\section{REFERENCES}

Becker, O. (1970), "Contributions towards the Phenomenological Foundation of Geometry and its Physical Applications", in Kockelmans and Kisiel (1970), pp. 119-146.

Boehm, R. (1964), "Les sciences exactes et I'idkal Husserlien d'un savoir rigoureux", Archives de Philosophic 27: 424-438.

Carr, D. (1974a), Phenomenology and the Problem of History. Evanston, Illinois: North-western University Press.

Courant, R. and Hilbert, D. (1924), Methoden der Mathematischen Physik. Berlin: SpringerVerlag.

Einstein, A. (1949), "Autobiographical Notes", in P. Schilpp (ed.), Albert Einstein: PhilosopherScientist. New York: Library of Living Philosophers, pp. 1-96.

Einstein, A. (1935/1954), "Physics and Reality", in C. Selig (ed.), Ideas and Opinions. Translated and revised by S. Bargmann. New York: Dell, pp. 283-315.

Elliston, F. and McCormick, P. (eds.) (1977), Husserl: Expositions and Appraisals. Notre Dame: Notre Dame University Press.

Fang, J. (1970), Hilbert: Toward a Philosophy of Modern Mathematics. Vol. II. Hauppauge, NY: Paideia.

Gurwitsch, A. (1966), "The Last Work of Husserl", in A. Gurwitsch, Studies in Phehenomelogy and Psychology. Evanston: Northwestern University Press, pp. 397-447.

Gutting, G. (1979), "Husserl and Scientific Realism", Philosophy and Phenomenological Research 39: $42-56$

Heelan, P. (1965), Quantum Mechanics and Objectivity. The Hague: Nijhoff.

Heelan, P.(1983a), Space-Perception and the Philosophy of Science. Berkeley and Los Angeles: University of California Press.

Heelan, P.(1983b), "Natural Science as a Hermeneutic of Instrumentation", Philosophy of Science 50: 181-204.

Heelan, P.(1983c), "Perception as a Hermeneutical Act", Review of Metaphysics 37: 61 75.

Heidegger, M. (1962), Being and Time. Translated by J. Macquarrie and E. Robinson. London: SCM Press.

Heisenberg, W. (1952), Philosophic Problems of Nuclear Science. London: Faber and Faber.

Hilbert, D. (1932-1935), David Hilbert Gesammelte Abhandlungen. Berlin: Springer-Verlag.

Hilbert, D. (1938), The Foundations of Geometry. (Original German edition published in 1901.) La Salle, Illinois: Open Court.

Hilbert, D. (1970), "Axiomatic Thinking", in Fang (1970), pp. 187-198. Originally published in Mathematische Annalen 78 (1918): 405-415; and republished in Hilbert (19321935), III.

Hooker, C. (1986), A Realist Theory of Science. Albany: SUNY Press.

Husserl, E. (1900/01), Logische Untersuchungen, 1 and 11. (2nd rev. ed., 1913.) Halle: Niemeyer. English translation by J. Findlay (1970), Logical Investigations, 2 vols. London: Routledge and Kegan Paul.

(Preprint 1987; “Husserl's Later Philosophy of Natural Science," Philosophy of Science, 


\section{Preprint 1987: Husserl's Later Philosophy of Natural Science}

Husserl, E. (1929), Formale and Transzendentale Logik. Halle: Niemeyer. English translation by D. Cairns (1969), Formal and Transcendental Logic. The Hague: Nijhoff.

Husserl, E. (1954), Erfahrung and Urteil. Edited by L. Landgrebe. Hamburg: Claasen. English translation by J. Churchill and K. Ameriks.

Husserl, E.(1973), Experience and Judgment. Evanston; Illinois: Northwestern University Press.

Husserl, E.(1950), Ideen zu einer reinen Phanomenologie and phanomenologische Philosophie. Volume I. Edited by Walter Biemel. Husserliana III. The Hague: Nijhoff.

Husserl, E. (1952a), Ideen zu einer reinen Phanomenologie and phanomenologische Philosophie. Volume 11. Edited by Marly Biemel. Husserliana IV. The Hague: Nijhoff.

Husserl, E. (1952b), Ideen zu einer reinen Phanomenologie and phanomenologische Philosophie. Volume 11[. Edited by Marly Biemel. Husserliana V. The Hague: Nijhoff.

Husserl, E.(1954), Die Krisis der europaischen Wissenschaften and die transzendentale Phanomenologie. Edited by Walter Biemel. Husserliana VI. The Hague: Nijhoff. English translation by D. Carr (1970), The Crisis of European Sciences and Transcendental Phenomenology. Evanston, Illinois: Northwestern University Press.

Husserl, E.(1970), Philosophie der Arithmetik (und Abhandlungen). Edited by L. Eley. Husserliana XII. The Hague: Nijhoff.

Ihde, D. (1979), Technics and Praxis. Dordrecht and Boston: Reidel.

Kisiel, T. (1970a), "Phenomenology as the Science of Science", in Kockelmans and Kisiel (eds.) (1970), pp. $5-44$.

Kisiel, T. (1970b), "Husserl on the History of Science", in Kockelmans and Kisiel (eds.) (1970), pp. 68-92.

Kisiel, T.(1973), "On the Dimensions of a Phenomenology of Science in Husserl and the Young Dr. Heidegger", Journal of the British Society for Phenomenology 4: 217-234.

Kisiel, T. (1977), "Heidegger and the New Image of Science", Research in Phenomenology $7:$ 162-181.

Klein, F. (1932/1939), Elementary Mathematics from an Advanced Standpoint. Translated by E. R. Hedrick and C. A. Noble. New York: Macmillan.

Kockelmans, J. (1970), "The Mathematization of Nature in Husserl's Last Publication", in Kockelmans and Kisiel (eds.) (1970), pp. 45-67.

Kockelmans, J.(1985), Heidegger and Science. Lantham, Maryland: University Press of America and Center for Advanced Research in Phenomenology.

Kockelmans, J. and Kisiel, T. (1970), Phenomenology and the Natural Sciences. Evans-ton, Illinois: Northwestern University Press.

Koyre, A. ([1939/1978), Galileo Studies. Translated by J. Mepham. Atlantic Highlands, New Jersey: Humanities Press.

Ladriere, J. (1970), "Mathematics in a Philosophy of the Sciences", in Kockelmans and Kisiel (eds.) (1970), pp. 443-465.

Landgrebe, L. (1977), "Phenomenology as Transcendental Theory of History", in Elliston and McCormick (1977), pp. 101-113.

Landgrebe, L. (1981), The Phenomenology of Edmund Husserl: Six Essays. Edited and with Introduction by D. Welton. Ithaca and London: Cornell University Press.

Mahnke, D. 0192311977), "From Hilbert to Husserl: First Introduction to Phenomenology, Especially that of Formal Mathematics", (translated by D. Boyer), Studies in History and Philosophy of Science 8: 71 -84.

Merleau-Ponty, M. (1962), The Phenomenology of Perception. Translated by C. Smith. London: Routledge and Kegan Paul.

Merleau-Ponty, M. (1968), The Visible and the Invisible. Translated by A. Lingis. Evanston: North-western University Press.

(Preprint 1987; “Husserl's Later Philosophy of Natural Science," Philosophy of Science, 54 (1987), 368-390. 
Mohanty, J. N. (1969), Edmund Husserl's Theory of Meaning. The Hague: Nijhoff.

Mohanty, J. N. (1974), "Life-World and A Priori in Husserl's Later Thought", Analecta Husserliana 3: 46-65.

Mohanty, J. N. (1977), "On Husserl's Theory of Meaning", in Elliston and McCormick (1977), pp. 1837.

Mohanty, J. N. (1982), Husserl and Frege. Bloomington: Indiana University Press. Natanson, M. (1964), "The 'Legenswelt", in Strauss (ed.) (1964), pp. 75-93. Nicholson, G. (1984), Seeing and Reading. Atlantic Highlands, New Jersey: Humanities Press.

Peirce, C. S. (1931-1958), Collected Papers of Charles Sanders Peirce, 8 vols.; vols. $1-6$ edited by C. Hartshorne and P. Weiss, vols. 7-8 edited by A. Burks. Cambridge, Massachusetts: Harvard University Press.

Sellars, W. (1963), Science. Perception, and Reality. London: Routledge and Kegan Paul. Sokolowski, R. (1964), The Formation of Husserl's Concept of Constitution. The Hague: Nijhoff.

Stevens, R. (1974), James and Husserl. The Hague: Nijhoff. . (1975), "Spatial and Temporal Models in Husserl's Ideas II", Cultural Hermeneutics 3: 105-116.

Straus, E. (ed.) (1964), Phenomenology: Pure and Applied. Pittsburgh: Duquesne University Press.

Stroker, E. (ed.) (1979), Lebenswelt and Wissenschaft in der Philosophic Edmund Hus serls. Frankfurt am Main: Klosterman.

Welton, D. (1983), The Origins of Meaning: A Critical Study of the Thresholds of Husserlian Phenomenology. The Hague: Nijhoff.

Weyl, H. (1194911963), Philosophy of Mathematics and Natural Science. New York: Atheneum.

Wigner, E. (1967), Reflections and Symmetries. Indiana University Press.

Zucker, F. J. (1982), "Phenomenological Evidence and the 'Idea' of Physics", in R. Bruzina and B. Wiltshire (eds.), Phenomenology Dialogues and Bridges. Albany: SUNY Press, pp. 269-290.

\section{NOTES}

1. By reality (and real) I mean the realm of natural or material being, that is, of res. Human beings are real. By real, I particularly do not want to imply elements knowable by us independently of their involvement in human life or characterized as having a suchness in themselves.

2. The Vienna Lecture" and "The Origins of Geometry" are included in the English translation of the Krisis by David Carr. These works are referred to in the text in the following way: C for Crisis, VL for "The Vienna Lecture," and OG for "The Origins of Geometry"; the number following is the page number in Carr's English translation. For an important review article on the Crisis, see Gurwitsch (1966b).

3. See Carr (1974a) and Kisiel (1970a) for studies of Husserl's notion of history, especially in the Crisis.

4. The principal text dealing with genetic phenomenology is Husserl (1929). See, for example, the excellent commentaries in Sokolowski (1964), Landgrebe (1977 and 1981), and Welton (1983).

5. Also see Husserl (1929 and 1954).

6. The Erlanger Programme sees geometry as essentially the study of forms that are invariant under group transformations of the mathematical space. Husserl, though not a geometer, would certainly have assimilated at Göttingen the central notion of the Erlanger Programme. His account of a perceptual eidos as an invariant under a group of transformations within a space of pragmatic-perceptual manipulations,

(Preprint 1987; “Husserl's Later Philosophy of Natural Science," Philosophy of Science, 54 (1987), 368-390. 
clearly reflects the influence of the Erlanger Programme. Moreover, Husserl shared with the members of the Gottingen group the view that mathematics and natural science were intimately related. See Klein (1932-1939), and Bulletin of the New York Mathematical Society 2 (1893): 115-149.

7. See Hilbert's essay "Axiomatisches Denken" in Mathematische Annalen (1918) and in Hilbert (1932-1935); English translation in Hilbert (1969).

8. The direct influence of Gottingen thinking is seen in the work of R.v. Mises and A.N. Kolmogorov on the foundations of probability. G. Hamel on the axiomatization of mechanics, and 1.v. Neumann on the axiomatic theory of quantum mechanics. Courant and Hilbert's Methoden der Mathematischen Physik (1924) astonished the new generation of quantum physicists by anticipating brilliantly the needs of the new physics and became the text from which directly or indirectly all theoretical physicists have been taught down to our own time.

9. See, for example, Einstein (1954), and (1949), "Autobiographical Notes", pp. 20-21. 48-49. See also Heisenberg (1952). Compare, for example, Hooker (1986) for a delentrf of this form of scientific realism.

10. Galilean science is a philosophical ideal type, some would say a reconstruction, of the kind used by Alexandre Koyre, for example, in his Galileo Studies ([1939] 1978). Koyrd was a pupil of Husserl at Gottingen and was strongly influenced by Husserl's early work on phenomenology. Historians of science today treat their historical sources more flexibly and do not feel constrained to use them just to determine the "origins" of present sedimented scientific traditions.

11. For the mutual influence of Hilbert and Husserl on one another, see Mahnke (1977), and Mohanty (1982), pp. 91 and 96. Husserl and Hilbert were both interested in axiomatic systems. For Husserl, see Logische Untersuchungen I, sections 69 and 70, and Husserliana X11, pp. 445-457. For Husserl's explicit references to Hilbert, see Husserl (1929), p. 96 in English translation, Abhandlungen VI and VII in Husserl (1970), pp. 445-457. Implicit references to Hilbert are found on pp. 45 and 55 of the Crisis. It was Hilbert who introduced the modern notion of a formal axiomatic system as the ideal form for all theory, whether mathematical or physical. See Hilbert ([1901] 1938); also his address "Axiomatic Thinking", (1918], in Hilbert (1969). It is worth comparing 1 Iusserl's thought and language with the words of Hilbert in this latter well-known address.

12. Most phenomenological studies of theoretical science emphasize the Cartesian and objectivist character of Galilean science, for example, Kisiel (1970a and 1970b), and Kockelmans (1970). The phenomenological tradition, as carried on through the works of Martin Heidegger, Maurice Merleau-Ponty, and their students, has seen itself as a movement that directly confronts "science" as its philosophical antagonist-the "science" in question is, of course, Husserl's Galilean science that is the philosophical core of the prevalent scientific tradition; see, for example, Boehm (1964) for such a polemic, and Merleau-Ponty (1962, pp. viii-ix).

13. or Husserl's notion of ideality, see Husserl (1900/01), volume II of the German edition. For the controversy surrounding its interpretation, see, for example, Mohanty (1969).

14. or the notions of essence and specific essence, see Husserl (1950 and 1952a). For an excellent commentary, see Stevens (1974, pp. 103-128).

(Preprint 1987; "Husserl's Later Philosophy of Natural Science," Philosophy of Science, 
15. ssociated with objectivism is technicism or the view that to know lies in the techni ${ }^{c}$ of calculating. Such a view reduces real causality to no more than the manifestation of a functionality between numerical values in an ideal space-time $(C, p$. 46). Technicism is the view that science contributes no ontological understanding to real perceptual life and that its function in human affairs is no more than to provide effective technical control over the environment. Many in the phenomenological tradition, such as Edward Ballard, Rudolf Boehm, Hans-Georg Gadamer, Maurice Merleau-Ponty, seem to be persuaded that all science is essentially and incorrigibly objective and theoretical, and would agree with Jurgen Habermas that the cognitive interest of the empirical-analytic sciences is technical control over objectified processes. Such a view, of course, reflects only one part-the negative part - of Husserl's critique of (the" most prevalent tradition of) positive science. See section 8 below for a criticism of technicism.

16. Husserl's "infinite perfectibility" of measurement is just a more intuitive way of ex-pressing Hilbert's formal axiom of continuity for physics; see Hilbert (1970).

17. See Landgrebe (1981, particularly pp. 38-42). The active and passive scenarios are, of course, related to Husserl's active and passive modes of constitution; for an account of the latter, see Stevens (1974, pp. 118-123).

18. Compare also notes 9,11 , and 19 and the relation of this view to the mathematical-physical work of Klein. Hilbert, and Wigner.

19. See Wigner (1967, Part I), where, following the inspiration of Felix Klein (see note 11) and Hilbert's extension of these ideas to physics, the reciprocity of passive and active transformation groups and their invariants and representations are shown to be basic to modern physics.

20. Sinn is contrasted with Bedeutung or the spoken judgment descriptive of the real. I follow in this matter the analysis of Welton (1983).

21.Current work in cognitive psychology on mental imagery, such as that of R. Shepard, may be relevant to this view.

22. See, for example, C, p. 129; also OG, p. 376 where Husserl comments on the praxis of making even surfaces by polishing.

23. Duhem's theme of the underdetermination of theory by experimental data has received new attention both from sociologists of science, such as $\mathrm{H}$. Collins, D. Gooding, D. Bloor, and from philosophers of science, such as M. Hesse, N. Cartwright, and I. Hacking.

24. Compare, for example, Husserl (1954, pp. 28-40). For discussion of Husserl's notion of the life-world, see, for example, Mohanty (1974), Natanson (1964), Landgrebe (1981, Essay 4, pp. 122-148), Ströker (1979), as well as the work of Alfred Schutz on the social world.

25. See Husserl (1954) for Husserl's use of the term "prepredicative".

26. Husserl's induction is more akin to C. S. Peirce's abduction than to Mill's induction; compare Peirce (1931-1958, 1.338, 2.228-2.308). For abduction as an interpretative act leading to a transformation of the perceptual field, see 5.182-5.184.

27. See, for example, "Philosophy and the Scientific Image of Man", pp. 1-40 in Sellars (1963).

28. See, for example, Merleau-Ponty (1962 and 1968), and Heelan (1983a).

29. Heelan (1983a).

30. For a defense of the thesis that all perception is hermeneutical, see Nicholson (1984) and Heelan (1983c). Outside the phenomenological tradition, compare the work of

(Preprint 1987; "Husserl's Later Philosophy of Natural Science," Philosophy of Science, 
Charles Saunders Peirce and Michael Polanyi.

31. For work on a hermeneutical theory of perception, see, for example, Heelan (1983a, 1983b, and 1983c), and Nicholson (1984). For Heidegger's relevance for the philosophy of science, see, for example, Kisiel (1977 and 1973), Kockelmans (1985), and the copious bibliography referenced there.

32. Hermann Weyl was the first to use phenomenology in a philosophy of the natural sciences, see Weyl (11949] 1963), but he was aware that physical conceptions are explored, as he says, by "another type of experience and imagination than those of the mathematician" (Hilbert 1932-1935, III, p. 653). An interest in a phenomenological interpretation of measurement as a praxis began with Heelan's study of the quantum theory, Heelan (1965). Notable also is the work of Zucker (1982). For the phenomenology of scientific technology and its influence on perception, see, for example, Ihde (1979), and Heelan (1975 and 1983a).

(Preprint 1987; “Husserl's Later Philosophy of Natural Science," Philosophy of Science, 